\title{
Knowledge, Attitudes, and Demographic Factors Influencing Cervical Cancer Screening Behavior of Zimbabwean Women
}

\author{
Sylvia C. Mupepi, Ph.D., Carolyn M. Sampselle, Ph.D., ${ }^{1}$ and Timothy R.B. Johnson, M.D. ${ }^{3}$
}

\begin{abstract}
Aims: The aims of this study were (1) to estimate what proportion of rural females had received cervical screening, (2) to assess knowledge, beliefs, attitudes, and demographics that influence cervical screening, and (3) to predict cervical screening accessibility based on demographic factors, knowledge, beliefs, and attitudes that influence cervical screening.

Methods: The study sample consisted of randomly selected, sexually active, rural females between 12 and 84 years of age. Five hundred fourteen females responded to an individually administered questionnaire.

Results: Of the 514 participants, 91\% had never had cervical screening and $81 \%$ had no previous knowledge of cervical screening tests; $80 \%$ of the group expressed positive beliefs about cervical screening tests after an educational intervention. Females who were financially independent were $6.61 \%$ more likely to access cervical screening compared with those who were dependent on their husbands. Females in mining villages were $4.47 \%$ more likely to access cervical screening than those in traditional rural reserve villages. Females in resettlement villages were $20 \%$ less likely to access cervical screening than those in traditional rural reserve villages.

Conclusions: Accessibility of screening services could be improved through planning and implementation of screening programs involving community leaders and culturally appropriate messages. The government should incorporate the human papillomavirus (HPV) vaccine in its immunization program for adolescents, and health education should be intensified to encourage women and their partners to comply with diagnostic and treatment regimens.
\end{abstract}

\section{Introduction}

$I^{\prime}$ N DEVELOPING COUNTRIES, cervical cancer is the leading female malignancy, but cervical screening is rare. ${ }^{1-3}$ With an estimated 473,000 annual cases of cervical cancer worldwide and 253,500 annual deaths, women in developing countries account for about $85 \%$ of both its morbidity and mortality. ${ }^{4}$ Cervical cancer is a deadly disease, even in developed countries. Of the estimated 10,000 women who are diagnosed with cervical cancer annually in the United States, 3,900 die from the disease. ${ }^{4}$ In developed countries, however, including the United States, death rates from cervical cancer have been dropping because regular cervical screening and treatment is available and accessible. ${ }^{5}$

In Zimbabwe, females as young as 15 years old continue to die from the disease, ${ }^{3}$ and studies indicate that cervical cancer continues to grow in the country. ${ }^{6}$ For example, in 1995, cervical cancer ranked number one, accounting for about $25 \%$ of all cancer mortality. ${ }^{3}$ In 2003, cervical cancer accounted for
$27.3 \%$ of all cancer deaths - still number one and an increase of $2.3 \%$ in less than 10 years in a population whose growth rate has been compromised by the HIV / AIDS pandemic. ${ }^{6}$

Cervical cancer is preventable if precancer is diagnosed early through screening and cured through treatment; it takes a long time for a human papillomavirus (HPV) infection to progress to precancer but less time in HIV-positive women. ${ }^{1}$ Although the etiology of cervical cancer is not really understood, it is known that genital HPV is directly associated with the disease. ${ }^{7-10}$ Further, it is now known that HPV 16 and HPV 18 may act synergistically to induce cervical neoplasia. ${ }^{11,12}$ Although HIV and HPV can be transmitted through other methods, they are both sexually transmitted diseases (STDs). ${ }^{11-13}$ Thus, all sexually active women have at least some level of risk for sexually transmitted infections (STIs), especially young women who have a high risk of acquiring HPV from polygamous relationships. ${ }^{1}$ An HPV vaccine provides immunity against the HPV strains that cause about $70 \%$ of the world's cervical cancers. ${ }^{5}$ However, to date, this vaccine is not

\footnotetext{
${ }^{1}$ Grand Valley State University Kirkhof College of Nursing, Grand Rapids, Michigan.

${ }^{2}$ University of Michigan School of Nursing and ${ }^{3}$ University of Michigan Medical School, Ann Arbor, Michigan.
} 
available to most of the population in Zimbabwe because of the competing health priorities in this developing nation.

Although it is known that cervical cancer can be cured through treatment if precancer is diagnosed early by screening, in sub-Saharan African countries, disease screening is not routine. In the African tradition, people do not access healthcare checkups or screening because the concept of a checkup is not known and is not common practice. ${ }^{6}$ Instead, people tend to access healthcare when they have disease symptoms. ${ }^{14}$

The first national cytology service for cervical cancer prevention in Zimbabwe was established in January 1972 to serve indigenous patients. ${ }^{15}$ Since that time, cervical screening has been available at hospital outpatient clinics, postnatal and family planning clinics, and gynecologic wards. Unlike screening programs in developed countries that target at-risk groups, in Zimbabwe there is no mass screening policy. ${ }^{16} \mathrm{Fe}-$ males who are screened include those who seek family planning services, particularly for medroxyprogesterone acetate (Depo-Provera); those with gynecologic symptoms; and those who request services from their healthcare providers. Typically, these are women who have knowledge of the disease and the means to pay. ${ }^{15,17,18}$ Little is known about females who do not access family planning and live in different rural settings, such as traditional reserve villages, farm villages, resettlement villages, and mine villages typically found in Zimbabwe.

This study, therefore, aims (1) to estimate what proportion of rural females had received cervical screening, (2) to assess knowledge, beliefs, attitudes, and demographic factors that influence cervical screening, and (3) to predict cervical screening accessibility based on demographic factors, knowledge, beliefs, and attitudes that influence cervical screening. This information is important for predicting cervical screening compliance and resource management for advancing the Government of Zimbabwe's cervical screening program.

\section{Background}

Zimbabwe's demographics. Zimbabwe, formerly known as Rhodesia, is a sub-Saharan African country located north of South Africa and west of Mozambique. It was a British colony until April 1980, when it attained self-rule after an armed struggle between the African natives and the Rhodesian European government. The only current census, conducted in 1992 before this study was done, counted 10.5 million people, of which $51 \%$ were women, and $86 \%$ of these women were living in rural areas. ${ }^{19}$ Ninety-eight percent of the population is African, and $2 \%$ consists of persons of European descent, Asians and Coloreds. ${ }^{* 120}$

Status of women in Zimbabwe. In accordance with the Roman-Dutch legal practices that governed this former British colony, women never attained full legal status. From birth to marriage, the woman was under the guardianship of her father or another male relative. Upon marriage she was transferred to the guardianship of her husband. Upon dissolution of the marriage by death or divorce, she reverted to the guardianship of her father or another male relative. ${ }^{21}$ Under this law, the woman became the property of her husband upon marriage and had no rights over her reproductive life; the husband made all decisions. Through tradition and custom, a

*The word "colored" is used in Zimbabwe Census and is a common concept in Southern Africa. woman was socialized to meet the demands of her husband and to be obedient to him; this was idealized as the "good wife." Having been socialized to the idea that they were minors for life and unequal to men, women were permanently unequal in their sexual relations with men. A woman had no right to discuss or refuse sex when her husband wanted it because he would threaten her with divorce. Divorce was economically untenable for women, and they were fearful of divorce because they walked away with no possessions.

This old law was repealed when the Zimbabwe Legal Age of Majority Act was passed after 1980 when Zimbabwe attained self-rule. ${ }^{21}$ However, tradition and custom have been slower to change. Unfortunately, the concept of gender roles, power, and male dominance over females has continued to facilitate the advancement of STIs and the HIV/AIDS pandemic in Zimbabwe. Whereas 31\% of all Zimbabweans live in urban areas, $86 \%$ of the women live in rural areas. Most men who work on commercial farms, in urban industries, or in mines leave their wives in rural homes because there are no provisions for family housing near these work sites, encouraging these men to engage in extramarital sexual relations, thereby increasing the risk of STIs.

In Zimbabwe, polygamy is practiced within customary law marriages as well as unregistered customary unions. One in five married Zimbabwean women is in a polygamous union. In addition to the risks posed by these marriages, violence intensifies the problem. In 1993, there were 2,315 reported cases of rape in Zimbabwe. The number of unreported rapes is, of course, unknown but assumed to be even greater. ${ }^{22}$ Polygamy is one of the sociocultural factors that may be responsible for cervical cancer in Africa. In some cultures, very old men with more than five wives may be given young virgins for wives. ${ }^{1}$ This may increase the risk of the virgin catching HPV at first intercourse with her husband.

HIV/AIDS in Zimbabwe. The adult prevalence of HIV/ AIDS in Zimbabwe is $24.6 \%$ of the total population, and there is a greater prevalence of HIV infections among women, with a ratio of 3:2. ${ }^{20}$ In the year 2000 , two of five women attending antenatal clinics in Harare, the capital of Zimbabwe, were HIV positive. Because HPV and HIV have been associated with cervical cancer, the high prevalence of infection foretells that the rate of cervical cancer is likely to continue to increase in the population.

Socioeconomic factors in Zimbabwe. Zimbabwe presents a mixed socioeconomic picture. For example, the literacy rate is improving. For those $\geq 15$ years of age, the literacy rate in $1989-1990$ was $85.1 \%$ for the total population (90\% male and $80 \%$ female). ${ }^{23}$ In 2003, the literacy rate for the same age group was estimated at $90.7 \%$ for the total population $(94.2 \%$ for males and $87.2 \%$ for females). ${ }^{24}$ Even though the literacy rate for women is higher in Zimbabwe compared to other subSaharan countries and $90 \%$ of expectant mothers receive antenatal care, with $70 \%$ delivering in health institutions, only $45 \%$ attend postnatal care, ${ }^{25}$ an opportunistic time to access cervical cancer prevention tests and treatment (as needed) before selection of a method of birth control. Employment and inflation present a different story. The national inflation rate was recorded in June 2007 at 2,200\%, and it has continued to rise. This trend of hyperinflation has negatively affected the health of Zimbabwe, which once had one of the best health 
progress records in sub-Saharan Africa. For example, basic food and health became increasingly inaccessible as the unemployment rate rose to $>80 \%$ in $2007 .{ }^{26}$ Zimbabwe's inflation rate remains the world's highest despite a controversial price freeze imposed in June 2007 in a bid to stem runaway price increases.

Along with many other health problems, the burden of cervical cancer diagnosis and care has been aggravated by these economic hardships and other factors, including (1) a cultural tendency to discriminate based on gender, (2) a lack of coherent public policies and knowledge about cervical screening, (3) a lack of trained cytotechnicians and gynecologists, (4) a lack of public education campaigns targeting women, and (5) a lack of healthcare providers to teach the importance of regular care and routine screening. ${ }^{16,27} \mathrm{Al}-$ though treatment exists for precancer lesions, it is not readily accessible for rural women or affordable for overburdened health systems.

This article reports for the first time about behavioral and demographic factors that influence cervical screening among rural women in Zimbabwe. We are not aware of any previously published studies that have been conducted in Zimbabwe to determine the extent to which some demographics, knowledge, beliefs, and attitudes of rural women affect their access to cervical cancer screening.

\section{Materials and Methods}

The study was conducted in Shamva, a rural district of Zimbabwe situated in Mashonaland Central Province about 116 kilometers from Harare, the capital of Zimbabwe. Based on the 1992 census, Shamva has a total of 21 administrative wards and a total population of 112,011 . The population of women aged 15-49 years was 25,107, but no figures were available for those aged $\geq 50$ years or $<15$. Eleven of these 21 wards comprise farm, mine, traditional rural reserve, and resettlement villages. ${ }^{19}$ The other 10 wards did not have a complete mix of these four villages typically found in rural Zimbabwe. Thus, the 4 villages are representative of the type of rural setting and healthcare access in this country.

Using the village names from the 11 wards, a random numbers table was used to draw the villages from which the study sample was obtained. The total number of villages from the 11 wards was 290. The breakdown of villages was as follows: 54 farm, 2 mine, 192 traditional rural reserve, and 42 resettlement villages. The total number of village community workers (VCWs) for the 290 villages was 29, with each VCW in charge of 10 villages. Using the village names, the villages for proportionate sampling were drawn as follows: 1 farm, 1 mine, 18 traditional rural reserve, and 8 resettlement villages, giving a total of 28 villages. The farm village was heavily populated compared with the mine and resettlement villages. There are also fewer mines compared to the number of farms in rural districts in Zimbabwe. The total population of females reported to be sexually active by the VCWs from the 28 villages was 3,052 . The population breakdown was as follows: 536 farm, 217 mine, 1,521 traditional rural reserve, and 778 resettlement villages.

\section{Sample size determination and power analysis}

A sample size of 400 subjects was considered to be sufficient for this study based on the research questions and power analysis. Power of 0.80 using an effect size of 0.25 and an alpha of 0.05 determined the sample size. Power of 0.80 , an effect size of 0.25 , and a significance level of 0.05 are generally viewed as adequate and standard because many statisticians use diverse figures based on type of studies. ${ }^{28-31}$ However, a decision to oversample was reached based on information from the district's health information analyst regarding the death rate related to HIV/AIDS among the target study population. Therefore, a population sample of 700 was considered large enough because it had a surplus of 300 participants. The VCWs generated the names of all females who met the study inclusion criteria. The names were entered into the computer for random selection after determining the proportionate samples.

\section{Proportionate sample allocation}

The population sampling fraction was derived from the formula

$$
f=n / N
$$

which is equal to $700 / 3,052=0.23 .^{30}$ Sample sizes within strata were obtained by multiplying the size of each by the sample fraction, yielding sample sizes of 121 farm, 50 mine, 350 traditional rural reserve, and 179 resettlement villages, for strata 1 through 4 , respectively. In proportionate allocation, the use of a uniform sampling fraction in each stratum generally attempts to produce a "population representative sample." ${ }^{\prime 30}$

Of the 700 subjects drawn for the study, 48 participated in six focus groups of 8 females from all four sample strata and were excluded from answering the questionnaire. The $48 \mathrm{fe}-$ males were excluded from answering the final questionnaire because they had already used the same instrument during the focus group discussion to revise the vocabulary and terminology used in the questionnaire for cultural effectiveness. Of the remaining subjects, 514 were interviewed and completed the questionnaire. Of those who completed the questionnaire, 91 were from farm, 34 from mine, 270 from traditional rural reserve, and 119 from resettlement villages (Table 1). One hundred of the rest were reported to have died, and 38 were absent from their homes at the time of the study. Of those who were reported dead or did not respond to the study invitation, 22 were from farm, 8 from mine, 56 from traditional rural reserve, and 52 from resettlement villages. There were approximately 1-2 weeks between the time of invitation and administration of the questionnaire. For those subjects who had given consent to participate and were ill, mostly from HIV-related conditions, 2 weeks was a long time to wait.

Oversampling was done in order to complete statistical procedures with adequate power. The researchers had no idea from day to day about how many invited subjects would have died or were likely to report for the interviews because the death rate from HIV/AIDS-related diseases was on the increase in that district at the time of data collection.

\section{Village types}

Farm villages. Farm villages consist of a collection of mud huts thatched with elephant grass arranged in compounds where farm workers live. These village compounds usually lack basic facilities, such as purified water and sanitation. There is no electricity; villagers use firewood and kerosene gas for energy. Commercial farms are owned by generations of former European settlers and affluent black Zimbabweans. 
Table 1. Demographic Characteristics and Cervical Screening Status of Sample $(n=514)$

\begin{tabular}{|c|c|c|c|c|}
\hline Variable & Number & $\%$ & $\begin{array}{l}\text { Number } \\
\text { ever had } \\
\text { screening }\end{array}$ & $\begin{array}{c}\% \text { ever } \\
\text { had } \\
\text { screening }\end{array}$ \\
\hline \multicolumn{5}{|l|}{ Marital status } \\
\hline Married & 361 & 70.2 & 41 & 8.0 \\
\hline Widowed & 98 & 19.1 & 7 & 1.4 \\
\hline Other & 55 & 10.7 & 3 & 0.6 \\
\hline \multicolumn{5}{|l|}{ Level of education } \\
\hline No formal education & 135 & 26.3 & 6 & 1.2 \\
\hline Elementary & 163 & 31.7 & 13 & 2.5 \\
\hline Middle school & 169 & 32.9 & 19 & 3.7 \\
\hline High school or more & 47 & 9.1 & 13 & 2.5 \\
\hline \multicolumn{5}{|l|}{ Religion } \\
\hline Christian & 430 & 83.7 & 46 & 8.9 \\
\hline Other & 84 & 16.3 & 5 & 1.0 \\
\hline \multicolumn{5}{|l|}{ Subject's age group, years } \\
\hline$<20$ & 86 & 17.9 & 10 & 2.1 \\
\hline $20-24$ & 117 & 24.3 & 14 & 2.9 \\
\hline $25-34$ & 107 & 22.2 & 18 & 3.7 \\
\hline $45+$ & 106 & 22.1 & 6 & 1.2 \\
\hline \multicolumn{5}{|l|}{ Subject's village } \\
\hline Rural reserve & 270 & 52.5 & 33 & 6.4 \\
\hline Rural resettlement & 119 & 23.2 & 6 & 1.2 \\
\hline Farm & 91 & 17.7 & 10 & 1.9 \\
\hline Mine & 34 & 6.6 & 2 & 0.4 \\
\hline \multicolumn{5}{|l|}{ Employment status } \\
\hline Housewife & 400 & 77.8 & 38 & 7.4 \\
\hline Unemployed/student & 67 & 13.0 & 7 & 1.4 \\
\hline Employed for wages & 47 & 9.2 & 6 & 1.2 \\
\hline \multicolumn{5}{|l|}{ Type of occupation } \\
\hline Peasant farmer & 337 & 65.6 & 32 & 6.2 \\
\hline Market vendor & 70 & 13.6 & 13 & 2.5 \\
\hline Farm laborer & 61 & 11.9 & 1 & 0.2 \\
\hline Other & 46 & 8.9 & 5 & 1.0 \\
\hline \multicolumn{5}{|l|}{ Financial situation } \\
\hline Dependent on husband & 317 & 61.7 & 35 & 6.8 \\
\hline Independent & 109 & 21.2 & 15 & 2.9 \\
\hline Dependent on other & 88 & 17.1 & 1 & 0.2 \\
\hline \multicolumn{5}{|l|}{$\begin{array}{c}\text { Annual household income, } \\
\text { in Zimbabwean dollars }\end{array}$} \\
\hline$<\mathrm{Z} \$ 5,000$ & 310 & 60.3 & 27 & 5.3 \\
\hline$\geq Z \$ 5,000$ or more & 204 & 39.7 & 24 & 4.7 \\
\hline \multicolumn{5}{|l|}{ Sexual history } \\
\hline Ever had sex & 509 & 99.0 & 51 & 9.9 \\
\hline \multicolumn{5}{|l|}{ Uterine status } \\
\hline No hysterectomy & 511 & 99.4 & 49 & 9.5 \\
\hline Had hysterectomy & 3 & 0.6 & 2 & 0.4 \\
\hline
\end{tabular}

Farm laborers are usually drawn from the poorly educated local rural population and migrant minorities from neighboring countries.

Some farms provide decent healthcare and school services for their workers through the state's farm workers health plan and state school funding. Others provide none. Farm health workers trained by the Ministry of Health and Child Welfare and employed by the farm provide limited services at health centers. These include treatment of minor ailments, such as headaches, toothaches, minor cuts and wounds, and animal and insect bites. Some farm health workers are also trained as traditional midwives and conduct normal vaginal deliveries. Lack of licensed healthcare providers limits access to specialist healthcare, such as cervical screening.

Mine villages. Mine villages contain modern, purposebuilt structures of brick under tile with built-in water and sanitary systems. The mine workforce is drawn from those who have a high school or college education and is recruited locally or internationally. Modern, well-equipped health centers serve these communities. They are staffed with qualified, licensed doctors and nurses employed by the mining corporations. The corporations also provide a health insurance plan and a retirement plan to all their members. This facilitates access to all types of primary care, including cervical screening.

Rural reserve villages. This type of village has mixed accommodations. Some have modern, purpose-built structures of brick under tile with built-in water and sanitary systems. Others are brick or mud under elephant grass thatch, with central water wells and Blair Ventilated-Improved-Pit (VIP) latrines. ${ }^{32}$ Some village homes have electricity; those without rely on firewood, kerosene, or solar power for energy. The villagers rely on peasant farming and microeconomic projects, such as poultry and piggery. Healthcare and education services are provided by the state, local rural councils, or church-related organizations. These rural health centers are staffed by trained and licensed doctors and nurses, with backup services from village health workers, traditional midwives, and licensed healers. The centers are located within a 10-kilometer radius from where people live.

Resettlement villages. Resettlement villages are comparatively new. In this scheme, families are moved from overcrowded rural reserve villages and are resettled on former commercial farms acquired by the state for this purpose. Some of these villages have modern housing with built-in sanitary facilities and piped water. Energy is provided by the state through a rural electrification scheme; in some instances, solar power has been provided by donors.

Many resettlement villages do not have their own health centers. Roads, schools, shopping facilities, and other infrastructure are usually undeveloped, except in a few places where village cooperatives have taken responsibility. Some families travel more than 10 kilometers to access healthcare and other necessities. Thus, access to services is poor, especially for the community's senior citizens and school children who cannot walk long distances in times of need. The health centers that do exist in resettlement villages have been provided by the state, local rural councils, or church-related organizations. As in the rural reserve villages, these health centers are served by trained and licensed doctors and nurses, with backup services from village health workers, traditional midwives, and licensed healers.

\section{Study design}

The Zimbabwe Ministry of Health and Child Welfare, the Medical Research Council of Zimbabwe, and the Institutional Review Board for Human Subjects Research Committee at the University of Michigan all initially approved the study, a descriptive survey. 
Participant selection. Twenty-nine VCWs provided census lists of females from 290 villages in half of the Shamva's district population. Using a proportionate allocation methodology, a total of 700 women were identified: 121 from farm villages, 50 from mine villages, 350 from traditional rural reserve villages, and 179 from resettlement villages. A random numbers table was used to draw names of potential subjects from a total population of 3,043 females who met the inclusion research criteria in the district. First, informed consent was obtained from each village head man to conduct this research among his villagers. A second informed consent was obtained from the individual potential subjects; they received an explanation of the research and were told they were free to decline or discontinue participation at any time without being disadvantaged in any way.

Study instrument. The instrument used in this study was adapted from those previously used with other populations. $\mathrm{Yu}$ et al. ${ }^{33}$ adapted the standard California Behavioral Risk Factor Surveillance System questionnaire for use with Asian Americans. We further adapted items for the Zimbabwean population. The questionnaire itself covered a range of issues, including (1) demographic and socioeconomic data, (2) cervical screening tests knowledge, (3) beliefs and attitudes toward cervical screening tests and cervical cancer, (4) reasons for accessing cervical screening, (5) health practices, and (6) perceptions of healthcare services.

Study procedures. To begin the study, six focus group discussions were conducted to refine the study questionnaire. With each focus group consisting of 8 participants, 48 of the 700 women participated in the focus group phase. The focus group responses were used to assess cultural appropriateness and understanding about clarity of the questionnaire. The questionnaire was revised and administered to the remaining 514 females. Based on whether they had ever heard of cervical cancer screening, the participants were divided into two groups. Group A included 98 (19\%) participants who had an understanding of and actual experience of cervical cancer screening, and group B included 416 (81\%) participants who had not heard about cervical cancer screening tests and lacked appreciable knowledge and experience about cervical screening tests and cervical cancer (Tables 2, 3, and 4). In order to administer the rest of the questionnaire to group B participants, it was necessary to provide onsite education. Using an educational pamphlet developed by the University of Zimbabwe Medical School at the department of obstetrics and gynecology in collaboration with the Ministry of Health and Child Welfare, supplemented with a plastic pelvic model, participants were updated. All participants were black Afri-

Table 2. Respondents' Cervical Screening STATUS $(n=514)$

\begin{tabular}{lcr}
\hline Variable & Number & $\%$ \\
\hline Ever had cervical screening test & & \\
No & 463 & 90.1 \\
Yes & 51 & 9.9 \\
Ever heard of cervical screening & 416 (group B) & 81.0 \\
No & 98 (group A) & 19.0 \\
Yes & & \\
\hline
\end{tabular}

Table 3. Respondents' Depth of Knowledge of Cervical SCREENING Before Instruction $(n=514)$

\begin{tabular}{lcc}
\hline Variable & Number & Percent \\
\hline $\begin{array}{l}\text { Respondent had in-depth } \\
\text { knowledge of cervical screening }\end{array}$ & & \\
Yes & 98 (group A) & 19.0 \\
No & 416 (group B) & 81.0 \\
\hline
\end{tabular}

can Zimbabwean females (Table 1). VCWs scheduled the questionnaire administration. Thus, the difference between group A and group B females was their knowledge of cervical screening tests.

Four professional public health nurses >age 40 were trained as research assistants to administer the questionnaire. These nurses and all the participants spoke the Shona language. The questionnaire was administered to each woman individually in a quiet, confidential setting, under trees and in backyards within the participants' villages. In general, each participant in group B required 1 hour for questionnaire completion, and each person in group A took about $30 \mathrm{~min}-$ utes. After completing the questionnaire, each participant received a bar of laundry soap and half a liter of cooking oil as a token of appreciation for participating in the study. Instructions and questions were back-translated from English to Shona and from Shona to English by a linguistics professor from the University of Zimbabwe.

Data analyses. The SPSS 8.0 Windows Statistical Software program was used to analyze the data. The cervical screening barrier scale had 20 items, with a Cronbach's reliability coefficient alpha of 0.75 . Cronbach's coefficient alpha measures internal consistency of a scale. Internal consistency is a high value representing good consistency among the variables constituting the scale. ${ }^{29-31}$ A 28-item belief scale had a Cronbach's reliability coefficient alpha of 0.70 . Principal component factor analysis was used to review associations in scale items.

Scale factor analysis. Three types of barriers emerged from the barrier scale factor analysis. We identified these as social, personal, and institutional.

\section{Barriers to accessing cervical screening}

The barriers to cervical screening identified in this study included the following: (1) the majority of females lacked knowledge about cervical screening tests and cervical screening, (2) most females lacked advice and encouragement by health professionals to access cervical screening, (3) most females could not afford the cost of cervical screening because of lack of health insurance, (4) a majority of females in resettlement villages had to walk long distances to a health facility, (5) most females had no access to cervical screening because it was not offered at their nearest health center, even at a 6-week postnatal examination, and (6) some females did not believe in their risk for cervical cancer because it was not in their family history.

In addition, four factors emerged from the belief scale factor analysis. We classified these as positive belief factors (e.g., Pap smear decreases chance of early death), negative belief factors (e.g., only commercial sex workers need cervical screening 
Table 4. Differences Between Women with (Group A) and without (Group B) Knowledge of Cervical Screening

\begin{tabular}{|c|c|c|c|c|c|}
\hline Predictor variable & $\beta$ & $S E$ & Adjusted OR & $95 \% C I$ & $\mathrm{p}$ value \\
\hline Had knowledge of screening & $-1.80^{* *}$ & 1.0 & 0.17 & $(0.06-0.45)$ & 0.00 \\
\hline Age $45+$ years & $-2.40^{*}$ & 1.20 & 0.09 & $(0.03-0.30)$ & 0.05 \\
\hline Market vendor & -3.33 & 2.03 & 0.04 & $(0.00-0.27)$ & 0.06 \\
\hline Resettlement village & -2.00 & 1.00 & 0.14 & $(0.05-0.37)$ & 0.07 \\
\hline Positive beliefs & 1.30 & 1.00 & 3.67 & $(1.35-9.97)$ & 0.07 \\
\hline
\end{tabular}

Logistic regression model: Predicting access to screening with demographics, beliefs, barriers, and knowledge variables.

${ }^{*} p<0.05 ; * * 0.01$.

$\mathrm{CI}$, confidence interval; odds ratio; SE, standard error.

test), positive misconceptions (e.g., cervical screening test cures cervical cancer and womb infection), and fatalistic misconceptions (e.g., cervical screening is a waste of money). A summary of the subscale items is reported in Table 5.

Knowledge scale. The scale had five items as follows: What is a cervical screening test? Why is the cervical screening test done? Who performs the cervical screening tests? What institution offers cervical screening tests? On what part of the body is the cervical screening test done? The Cronbach's reliability coefficient alpha for this scale was 0.74 . Perceptions about healthcare services scale consisted of seven items with a Cronbach's reliability coefficient alpha of 0.75 . Two questions assessed cervical screening status of females. Ever accessed cervical screening tests and Ever heard of cervical screening tests were measured by a Yes and No response format (Table 2). Bivariate analyses were used to analyze the relationship between the dependent variables, Ever accessed cervical screening tests and Ever heard of cervical screening tests, and the independent variables, age, village, educational level, religion, marital status, financial dependence, and financial income. Chi-square was used for categorical variables, and Student's $t$ test was used for continuous variables. Statistical significance for all tests was assessed at the 0.05 level.

\section{Results}

The most important results emerging from this study were in response to our study aims: (1) to estimate what proportion of rural females had received cervical screening, (2) to assess knowledge, beliefs, attitudes, and demographic factors that influence cervical screening, and (3) to predict cervical screening accessibility based on demographic factors, knowledge, beliefs, and attitudes that influence cervical screening.

Of the 514 participants, 91\% had never had cervical screening, and $81 \%$ had no previous knowledge of the cervical screening tests. Despite never having had cervical screening and lacking prior knowledge of its purpose, $80 \%$ of the females expressed positive beliefs about cervical screening tests after an educational intervention. Females who were financially independent were $6.61 \%$ more likely to access cervical screening tests compared with those who were dependent on their husbands. Females from the mining villages were $4.47 \%$ more likely to access cervical screening tests compared with those in traditional rural reserve villages. Those females who lived in resettlement villages were $20 \%$ less likely to access cervical screening than those who lived in traditional rural reserve villages.

\section{Predictors of cervical screening tests}

A logistics regression model with group A and group B participants combined was run and analyzed with Ever accessed cervical screening as the dependent variable and demographic items, belief scale items, and barrier scale items and knowledge as independent variables to predict factors that may influence accessing of cervical screening. Odds ratios (ORs) were used to measure the degree of association of independent variables and dependent variables (Table 4).

Knowledge of a cervical screening test was a significant factor. Females who had prior knowledge of cervical screening tests were $83 \%$ more likely to access cervical screening compared to those who had no prior knowledge (OR 0.17, $p=0.00)$. Age was a significant factor. Women aged $\geq 45$ years had a $90 \%$ less chance of accessing cervical screening compared with women between 25 and 34 years old (OR 0.10, $p=0.05)$. The participants' occupations were a significant factor. Females who worked as market vendors had $96 \%$ less chance of accessing cervical screening compared with females who were peasant farmers (OR 0.04, $p=0.06$ ).

The village where the participant resided also was a significant factor. Females who lived in resettlement villages had an $86 \%$ less chance of accessing cervical screening compared with females who lived in traditional rural reserve villages (OR $0.14, p=0.07$ ). A 1.30 point increase in the positive belief scale was associated with a $3.33 \%$ increase in the likelihood of accessing cervical screening (OR 3.67, $p=0.07$ ). After controlling for institutional barriers and positive beliefs, the respondent's type of village was significantly associated with the likelihood of accessing cervical screening $(p=0.00)$. Specifically, females from resettlement villages had only about one-fifth the likelihood of accessing cervical screening compared with females in the traditional rural reserve villages (OR 0.20, $p=0.04$ ). Females from the mining villages had a $4.47 \%$ chance of accessing cervical screening compared with females in the traditional rural reserve villages (OR 4.53, $p=0.00)$.

After adjusting for village and institutional barriers, a 1.61 point increase in the positive belief scale was significantly associated with a 5-fold increase in the likelihood of accessing cervical screening (OR 5.00, $p=0.00$ ). Also, after controlling for village and positive beliefs, an 0.70 point decrease in the institutional barriers scale was associated with halving of the likelihood of accessing cervical screening (OR 0.50, $p=0.01$ ).

Finally, the participant's financial situation was significantly associated with the likelihood of accessing cervical screening $(p=0.05)$ after adjusting for village, institutional barriers, and positive beliefs. Specifically, females who were 
Table 5. Subscales in Cervical Screening BARRIER AND BELIEF SCAlE

Subscale Belief items

Social barriers

Husband would not permit

Afraid I would be considered immoral

Never heard of cervical screening

Embarrassed and shy

Health center is too far

Personal barriers Cervical screening

is uncomfortable/painful

Do not have time

Cervical cancer is not in my family

Cervical screening is not offered at nearest health center

Institutional barriers No one advised me to have cervical screening

Cervical screening expensive; cannot afford it

No health insurance

Positive beliefs Cervical screening is effective

Cervical screening is worthwhile

Will benefit from cervical screening

Cervical screening provides chance of cure

Cervical screening decreases chance of early death

Cervical screening will protect future health

Treatment less severe

Effective ways to treat cancer

Negative beliefs

Positive misconceptions

Fatalistic misconceptions financially independent had a $6.61 \%$ greater chance of accessing cervical screening compared with those who were dependent on their husbands (OR 7.39, $p=0.02$ ). This variable had the largest effect on the likelihood of accessing cervical screening.

\section{Discussion}

The major findings in this study were that $90 \%$ of the participants had never accessed cervical screening and $81 \%$ of the sample (i.e., group B) had no previous knowledge of cervical screening tests. These findings are similar to those of other researchers in sub-Saharan countries, such as Botswana, Cameroon, Kenya, Tanzania, Uganda, South Africa, Nigeria, and Ghana. ${ }^{34-49}$ Of most importance, 45 of 379 females who had formal education had accessed cervical screening compared to 6 of 135 women without formal education (Table 1). Women between the ages of 25 and 34 were more likely to access cervical screening compared with those $\geq 45$ years. In Zimbabwe, young females of childbearing age with formal education who can pay for healthcare and typically attend family planning services have access to cervical screening services because cervical screening is done routinely on all women who receive contraceptives. Those who are aged $\geq 45$, have little or no formal education, lack knowledge of cervical screening, lack health insurance, and have no disease symptoms are less likely to patronize health centers for any form of checkup.

Females who worked as market vendors were less likely to access cervical screening compared with those who worked as peasant farmers. This is logical. In Zimbabwe, females who work as market vendors travel long distances to sell their products and are away from home for long periods, which reduces their chances of regular contact with healthcare providers. Those who work as peasant farmers are based in their villages near their farm fields and healthcare centers.

One of the most important findings from this study is that females from resettlement villages had less chance of accessing cervical screening compared with those from traditional rural reserve villages. Earlier in this article, we discussed a few of the problems faced by women who live in resettlement villages. Some villages have no health centers. If services are available, they are sometimes located at unreasonable distances, often lack medicines and healthcare personnel, and sometimes do not have basic diagnostic equipment. Transportation is a major problem because there is no developed road service between available health centers and the resettlement villages. Local rural resettlement councils and church organizations that administer resettlement health centers largely depend on unreliable donations from the state and private organizations for their financial survival. Services provided at better-equipped health centers, which are built and administered by a government loan from the World Bank, are usually oversubscribed and congested, causing shortages in medicines and other resources. Historically, it is known that the Zimbabwean government has a controversial rural resettlement program that allocates its citizens land and settles them on the farms bought or repossessed by the government. We have already discussed some of the challenges caused by this scheme. It is incumbent upon the government administration to promote the health of its 
citizens by planning and providing safe and healthy infrastructures before settling its citizens in these villages.

A further finding from these study results is that females from the mining villages have the best chance of accessing cervical screening. We know that Zimbabwe's economy is heavily subsidized by the mining industry, and we described how the private cooperatives provide for their workers. It is not surprising that females from the mining villages have the best opportunities to access cervical screening, as long as they are encouraged by healthcare providers to do so and are taught about the importance of regular screening and checkups. We also know that the village mine health centers are staffed by licensed nurses and doctors and have the best equipment to keep their workforce and families healthy.

Knowledge of the impact of status of females on cervical screening is a major finding of this study. The individual female's financial situation was a very significant finding in this study. It showed that females who were financially independent had a better chance of accessing cervical cancer screening compared with those who were financially dependent on their husbands or family relatives. Zimbabwe and most of the sub-Saharan African countries are strongly patriarchal in culture. We know that cervical cancer is associated with HPV infections, which are sexually transmitted, and that symptoms appear only when the disease is at an advanced, incurable stage. In addition, we know that in sub-Saharan countries, the concept of disease screening is not well known and not regularly practiced. When a female who depends on her husband for healthcare asks for screening for an STD, she may have to answer questions relating to marital infidelity and accusations of promiscuity. Whether or not females will be able to obtain money for cervical screening depends on what men know and believe about it. The majority of females in this position are those who live in the rural villages. Abrahams et al. ${ }^{35}$ reported that in South Africa, some females mentioned not being allowed to visit clinics for contraceptive services and were even beaten by their husbands for attending mobile health clinics without their permission. Although females in Zimbabwe and South Africa are protected by national laws, most of the rural females are very traditional. They are afraid and reluctant to report men who question or beat them because according to tradition, they are supposed to be subservient to their husbands.

The barriers to cervical screening identified in this study include (1) females lacked knowledge about cervical screening tests and cervical screening, (2) lack of advice and encouragement by health professionals to females to access cervical screening, (3) most females could not afford the cost of cervical screening because of lack of health insurance, (4) health facility was too far away, (5) dependence on subsistence farming causes hardships and poverty, (6) lack of access to cervical screening because it was not offered at their nearest health center, even at a 6-week postnatal examination when it it suppose to be available, and (7) some females did not believe in their risk for cervical cancer because it was not in their family history. Some of these barrier are not new; Tarwireyi ${ }^{40}$ discussed them in a study conducted in the Mutoko rural district in Zimbabwe

Anorlu, ${ }^{1}$ Machoki and Rogo, ${ }^{34}$ Ajayi and Adewole, ${ }^{36}$ and Adanu ${ }^{39}$ identified similar barriers in sub-Saharan countries. Hoffman et al. ${ }^{50}$ reported poverty, age, and increasing education as the main predictors of health service use, and Are- vian et al. ${ }^{51}$ reported that educational level and perceived economic status were significantly correlated to knowledge and practices of cervical cancer screening in developing countries. In this study, we found that females who had prior knowledge of cervical screening had greater chances of accessing cervical screening. $\mathrm{Yi}^{52}$ reported that level of education, income, and marital status contributed significantly toward cervical screening among Vietnamese and Cambodian women living in the United States.

\section{Conclusions}

This study showed that knowledge of cervical screening and accessibility were very low despite high literacy rates among rural women and even when primary healthcare clinics are available. We recommend that the Government of Zimbabwe should acknowledge and recognize that cervical cancer is a major public health concern and accord its prevention and treatment priority in resource allocation. There is a critical need to intensify mass education on the prevention of STIs, targeting especially adolescents and young adults, who are at higher risk for the disease, to inform them of the role of $\mathrm{HPV}$ in HIV-infected women and to promote both HIV screening and regular cervical screening. Efforts should be made to target traditional leaders who support customary polygamous marriage practices because this practice increases the risk of HPV infections in young women. The education curricula of nurses and physicians should incorporate promoting cervical cancer screening and treatment so graduates can increase awareness and encourage their clients to participate in the program. Cervical cancer screening and treatment should be incorporated into the Zimbabwe Maternal Child Health program and accorded the same priorities as those of HIV, childhood immunizations, malnutrition, malaria, and tuberculosis.

The HPV vaccine, for example (Gardasil, Merck \& Co., Whitehouse Station, NJ), a recombinant vaccine that targets and protects against the HPV strains that cause cervical cancer, is now being offered to females between 9 and 26 years old in the United States. ${ }^{53}$ Through the Zimbabwe Expanded Program on Immunization (ZEPI), young women could be immunized against this disease. A male vaccine that has been in clinical trials can also be incorporated into the immunization program of adolescents.

Unfortunately, the Gardasil vaccine is expensive and may not be easily accessible to many people. Even though developing countries have competing priorities in their health budgets and cannot afford universal immunization coverage for their adolescent populations, they have the responsibility to inform their citizens about this vaccine and its effects so that those citizens who can afford it can access the vaccine. With the availability of this new HPV vaccine and the controversy that surrounds its administration, it is important for governments to seek a dialogue with community representatives to dispel the myths that surround the use of immunizations in young women. Communication of culturally appropriate messages that address women's concerns and correction of misconceptions may encourage women to access cervical screening. ${ }^{54}$

Zimbabwe provides health science laboratory training programs for the Southern African Development Community (SADC) through the University of Zimbabwe Medical School in Harare, the National University of Science and Technology 
(NUST) in Bulawayo, and other state and private universities in the country. The laboratory technicians from these institutions could be deployed to rural health centers to process cervical screening tests. In the absence of high-cost technology to process Pap smears, such cost-effective screening measures as the visual inspection with acetic acid (VIA) technique could be a viable choice. The VIA test can be done by trained nurses, with results available on site. VIA has been tested in Zimbabwe for sensitivity, specificity, and predictive value but is not yet offered for mass screening. ${ }^{55}$

\section{Limitations of this study}

The majority of females in this study sample had no knowledge of or actual experience of cervical screening test; consequently, their responses were hypothetical as opposed to real experiences. A more nuanced interpretation of the data accepts the subtle distinctions between self-reported behaviors and externally based observations, which might limit the extent of the validity of self-reported behavior. Of the 700 females targeted for the questionnaire, only 514 responded. The unrepresented views of 186 females who dropped out of the study for diverse reasons and the sampling strategy of choosing 1 farm from 54 and 1 mine from 2 might limit the extent of the validity and generalizability of the results. Although proportionate sampling was used to determine the study sample population, final data analysis did not incorporate proportionate analysis strategy, which might limit the validity of the study results.

\section{Acknowledgments}

We thank the Zimbabwe Ministry of Health and Child Welfare for their cooperation and assistance with this study; Drs. Debra Oakley, Cynthia Coviak, Jan Andersen, and Anthony Schork for consultation throughout the study; and especially the enthusiastic Zimbabwean women who participated. This study was funded in part by the W.K. Kellogg Foundation and the Center for African American and African Studies at the University of Michigan.

\section{Disclosure Statement}

The authors have no conflicts of interest to report.

\section{References}

1. Anorlu RI. Cervical cancer: The sub-Saharan African perspective. Reprod Health Matters 2008;16:41-49.

2. Lovejoy NC. Multinational approaches to cervical cancer screening: A review. Cancer Nurs 1996;19:126-134.

3. Chokunonga E. Patterns of cancer in Zimbabwe: Zimbabwe National Cancer Registry Annual Report 1995. Harare: Government Printers, 1997.

4. National Cervical Cancer Coalition. Cervical cancer screening saves lives. Available at www.nccc-online.org/

5. Dailard C. HPV in the United States and developing nations: A problem of public health or politics? Guttmacher Rep Public Policy 2003;6:4-6.

6. Chokunonga E, Borok MZ, Nyakabau AM. Patterns of cancer in Zimbabwe: Zimbabwe National Cancer Registry Annual Report, 2003.

7. Bosch FX, Manos MM, Munoz N, et al. Prevalence of human papillomavirus in cervical cancer: A worldwide perspective.
International Biological Study on Cervical Cancer (IBSCC) Study Group. J Natl Cancer Inst 1995;87:796-802.

8. Franco EL. Cancer causes revisited: Human papillomavirus and cervical neoplasia. J Natl Cancer Inst 1995;87:779-780.

9. Kenney JW. Risk factors associated with genital HPV infection. Cancer Nurs 1996;19:353-359.

10. Yamada T, Manos MM, Peto J, et al. Human papillomavirus type 16 sequence variation in cervical cancers: A worldwide perspective. J Virol 1997;71:2463-2472.

11. Fuchs PG, Girardi F, Pfister H. Human papillomavirus DNA in normal, metaplastic, preneoplastic and neoplastic epithelia of the cervix uteri. Int J Cancer 1988;41:41-45.

12. Cu-Uvin S, McLean C, Flanagan TP, Fiore T, Jesdale B, Piepert J. Cervical cytologic abnormalities in HIV-seropositive women: Cytologic and histologic correlation. Womens Health. 1994;3:179-184.

13. Chin KM, Sidhu JS, Janssen RS, Weber JT. Invasive cervical cancer in human immunodeficiency virus-infected and uninfected hospital patients. Obstet Gynecol. 1998;92:83-87.

14. Frost O. Some aspects of the problem of carcinoma of the cervix in Zimbabwe. Cent Afr J Med 1981;27:169-171.

15. Frost O. Evaluation of Rhodesian cytology. S Afr Med J 1972;46:1444-1446.

16. Moyo IM, Koni NP, Makunike B, Hipshman J, Makaure HK, Gumbo N. Evaluation of cervical cancer screening programme in the Harare City Health Department, Zimbabwe. Cent Afr J Med 1997;43:223-225.

17. Chirenje ZM, Rusakaniko S, Chipato T, et al. Situation analysis for cervical cancer diagnosis and treatment in Zimbabwe. Cent Afr J Med 1998;44:307-310.

18. Thistle PJ, Chirenje ZM. Cervical cancer screening in a rural population of Zimbabwe. Cent Afr J Med 1997;43:246-251.

19. Chipiro-Mupepi SC. Cervical cancer screening: Perceptions of women in sub-Saharan cultures: An example of Zimbabwe. Dissertation. Ann Arbor, MI: School of Nursing, University of Michigan, 2001.

20. World development indicators, 1998. Washington, DC: World Bank, 1998.

21. Armstrong A, Ncube W. Women and law in southern Africa. Harare, Zimbabwe: Zimbabwe Publishing House, 1987.

22. Women of the world: Laws and policies affecting their reproductive lives: Anglophone Africa. New York: Center for Reproductive Law and Policy, 1997.

23. Statistical yearbook. Paris: United Nations Educational, Scientific and Cultural Organization (UNESCO), 1996.

24. Central Intelligence Agency. The world factbook 2007. Country statistics: Zimbabwe. Available at www.cia.gov/ library/publications/the-world-factbook/ Accessed December 16, 2007.

25. Women's health in Zimbabwe: A path to development. Zimbabwe: Ministry of Health and Child Welfare, 1994.

26. Schrank P. Back to the dark ages: Zimbabwe. Economist May 17, 2007.

27. Mupepi SC, Mupepi MG, Tenkasi RV, Sorensen PF Jr. Changing the mindset: Transforming organizations into high energized and performance organizations. Paper presented at 49th Midwest Academy of Management on Leading and learning: What's ahead for management education, October 14, 2006, Louisville, KY.

28. Cohen J. Statistical power analysis for the behavioral sciences, 2nd ed. Hillsdale, NJ: Lawrence Erlbaum Associates, 1988.

29. Cohen J. A power primer. Psychol Bull 1992;112:155-159. 
30. Pedhazur EJ, Schemelkin L. Measurement, design and analysis: An integrated approach. Hillsdale, NJ, Hove, London: Lawrence Erlbaun Associates, 1991.

31. Munro BH. Statistical methods for healthcare research. Philadelphia: Lippincott, 1997.

32. Morgan P. Rural water supplies and sanitation. London and Basingstoke: Macmillan, 1990.

33. Yu MY, Seetoo AD, Tsai CK, Sun C. Sociodemographic predictors of Papanicolaou smear test and mammography use among women of Chinese descent in southeastern Michigan. Womens Health Issues 1998;8:372-381.

34. Machoki JM, Rogo KO. Knowledge and attitudinal study of Kenyan women in relation to cervical carcinoma. Int J Gynaecol Obstet 1991;34:55-59.

35. Abrahams N, Wood K, Jewkes R. Barriers to cervical screening: Women's and health workers' perceptions. Curationis 1997;20:50-52.

36. Ajayi IO, Adewole IF. Knowledge and attitude of general outpatient attendants in Nigeria to cervical cancer. Cent Afr J Med 1998;44:41-43.

37. Pillay AL. Rural and urban South African women's awareness of cancers of the breast and cervix. Ethn Health 2002;7: 103-114.

38. Wellensiek N, Moodley M, Moodley J, Nkwanyana N. Knowledge of cervical cancer screening and use of cervical screening facilities among women from various socioeconomic backgrounds in Durban, Kwazulu Natal, South Africa. Int I Gynecol Cancer 2002;12:376-382.

39. Adanu RM. Cervical cancer knowledge and screening in Accra, Ghana. J Womens Health Gend Based Med 2002;11: 487-488.

40. Tarwireyi F. Perceptions and barriers to cervical cancer screening in a rural district of Mutoko, Mashonaland East Province, Zimbabwe. Cent Afr J Med 2005;51:120-122.

41. Abotchie PN, Shokar NK. Cervical cancer screening among college students in Ghana: Knowledge and health beliefs. Int J Gynecol Cancer 2009;19:412-416

42. McFarland DM. Cervical cancer and Pap smear screening in Botswana: Knowledge and perceptions, International Council of Nurses. Int Nurs Rev. 2003;50:167-175.

43. Gichangi P, Estambale B, Bwayo K, Rogo S, Ojwang S, Opiyo A. Knowledge and practices about cervical cancer and Pap smear testing among patients at Kenyatta National Hospital, Nairobi, Kenya. Int J Gynecol Cancer 2003;13:827-833.

44. Gatune JW, Nyamongo IK. An ethnographic study of cervical cancer among women in rural Kenya: Is there a folk causal model? Int J Gynecol Cancer 2005;15:1049-1059.

45. Kidanto HL, Kilewo CD, Moshiro C. Cancer of the cervix: Knowledge and attitudes of female patients admitted at
Muhimbili National Hospital, Dar Es Salam. East Afr Med J 2002;79:467-475.

46. Mutyaba T, Mmiro F, Weiderpass E. Knowledge, attitudes and practices on cervical cancer screening among the medical workers of Mulago Hospital, Uganda. BMC Med Educ 2006;6:13.

47. Mangoma JF, Chirenje MZ, Chimbari MJ, Chandiwana SK. An assessment of rural women's knowledge, constraints and perceptions on cervical cancer screening: The case of two districts in Zimbabwe. Afr J Reprod Health 2006;10:91-103.

48. Moodley J, Harries J, Barone M. Misinformation and lack of knowledge hinder cervical cancer prevention. $\underline{\mathrm{S} \text { Afr Med J }}$ 2009;99:128.

49. Tebeu PM, Major AL, Rapiti E, et al. The attitude and knowledge of cervical cancer by Cameroonian women: A clinical survey conducted in Mroua, the capital of Far North Province of Cameroon. Int J Gynecol Cancer 2008; 18:761765.

50. Hoffman M, Pick WM, Cooper D, Myers JE. Women's health status and use of health services in a rapidly growing periurban area of South Africa. Soc Sci Med 1997;45:149-157.

51. Arevian M, Noureddine S, Kabakian T. A survey of knowledge, attitude, and practice of cervical screening among Lebanese/Armenian women. Nurs Outlook 1997;45: $16-22$.

52. Yi JK. Factors associated with cervical cancer screening behavior among Vietnamese women. J Community Health 1994; 19:189-200.

53. Centers for Disease Control and Prevention. Summary of recommendations for childhood and adolescent immunization. Available at www.immunize.org/catg.d/p2010.pdf

54. Agurto I, Arrossi S, White S, et al. Involving the community in cervical cancer prevention programs. Int J Gynecol Obstet 2005;89:538-545.

55. Gaffikin L, Blumenthal P, McGrath J, et al. Visual inspection with acetic acid for cervical-cancer screening: Test qualities in a primary-care setting. University of Zimbabwe/JHPIEGO Cervical Cancer Project. Lancet 1999;353:869-873.

Address correspondence to: Sylvia. C. Mupepi, Ph.D. Associate Professor, Kirkhof College of Nursing Grand Valley State University Room 472, Cook-DeVos Center for Health Sciences 301 Michigan Street, NE Grand Rapids, MI 49503-3314

E-mail: mupepis@gvsu.edu 


\section{This article has been cited by:}

1. Claudine Akono Ayissi, Richard G. Wamai, Geofrey O. Oduwo, Stacey Perlman, Edith Welty, Thomas Welty, Simon Manga, Javier Gordon Ogembo. 2012. Awareness, Acceptability and Uptake of Human Papilloma Virus Vaccine Among Cameroonian School-Attending Female Adolescents. Journal of Community Health . [CrossRef]

2. Richard G. Wamai, Claudine Akono Ayissi, Geofrey O. Oduwo, Stacey Perlman, Edith Welty, Simon Manga, Javier Gordon Ogembo. 2012. Assessing the Effectiveness of a Community-Based Sensitization Strategy in Creating Awareness About HPV, Cervical Cancer and HPV Vaccine Among Parents in North West Cameroon. Journal of Community Health . [CrossRef] 